\title{
Successful Therapeutic Management of Theileriosis in a Goat- A Case Report
}

\author{
P.R. Banka, S. Sivaraman*, G. Vijayakumar and A. Arulmozhi
}

Department of Veterinary Clinical Medicine, Veterinary College and Institute, Namakkal, Tamil Nadu 637 002, Tamil Nadu Veterinary and Animal Sciences University, India

*Corresponding author

\section{A B S T R A C T}

Keywords

Theileria, Caprine, Koch's blue bodies, Schizont

Article Info

Accepted:

10 April 2020

Available Online:

10 May 2020
A rare case of caprine theileriosis is described and discussed in this report. A three years old female non-descript, goat was brought to the Small Ruminant Care Unit, Teaching Veterinary Clinical Complex, Veterinary College and Research Institute, Namakkal with the history of anorexia, and prostation. Detailed examination revealed rough coat, emaciation, prostration, inability to get up, pyrexia $\left(41^{\circ} \mathrm{C}\right)$, tachycardia, slightly icteric mucus membranes, enlarged lymph nodes, decreased haemoglobin $(7.2 \mathrm{~g} /$ dl), decreased haematocrit (20.29\%), increased leukocyte count (19.84 x103cu.mm), increased red blood cell distribution width (33\%) and presence of "Koch's blue bodies" in lymph node biopsy smear.

\section{Introduction}

Theileriosis is a tick-borne haemoprotozoan disease caused by protozoan species belonging to the genus Theileria. These are obligatory intracellular parasites of the family Theileriidae that are known to infect wild and domestic ruminants in tropical and subtropical regions of the world (Dolan, 1989). The disease being a major threat to livestock industry and has become a constraint in goat production by causing economic losses in terms of high morbidity and mortality. In
India $T$. hirci and $T$. ovis are the most prevalent species reported in small ruminants (Sisodia, 1981; Kaufmann, 1996).

\section{Case history}

A three years old female non-descript, goat weighing about $20 \mathrm{~kg}$ was brought to the Small Ruminant Care Unit, Teaching Veterinary Clinical Complex, Veterinary College and Research Institute, Namakkal with the history of anorexia, and prostration. 


\section{Clinical examination}

Routine clinical examination revealed rough coat, emaciation, prostration, inability to stand up, lethargy, pyrexia $\left(41^{\circ} \mathrm{C}\right)$, tachycardia, slightly icteric mucous membrane, enlarged lymph nodes and presence of ticks over the inner aspect of the ears.

\section{Haematological observations}

Decreased haemoglobin $(7.2 \mathrm{~g} / \mathrm{dl})$, decreased haematocrit $(20.29 \%)$, increased leukocyte count (19.84 x103cu.mm.), increased red blood cell distribution width (33\%) indicates alterations in osmolality of circulating blood that decreases the ability of red blood cells undergo deformation under certain pathophysiological conditions which results low microvascular perfusion and organ dysfunction.

\section{Lymph node smear examination}

Lymph node smears were obtained by fine needle aspiration biopsy (FNAB) method to study the lymphadenopathy as there were enlarged lymph nodes during clinical examination.

The lymph node smears were subjected to both Leishman and Giemsa stain. Presence of intra-lymphocytic schizonts namely "Koch's blue bodies" (Fig. $1 \&$ 2) clearly indicated that the case was caprine coccidiosis.

\section{Treatment}

The goat was treated with Buparvoquone $(2.5 \mathrm{mg} / \mathrm{kg} \mathrm{Bwt} \mathrm{IM})$ and repeated another dose at $48 \mathrm{hrs}$ interval.

Inj.Oxytetracycline $(20 \mathrm{mg} / \mathrm{kg}$ Bwt IV with Normal saline and Vit B-complex (3ml IM), ) for three days daily.

\section{Results and Discussion}

Poor general condition, rough coat, emaciation, dullness, depression, anorexia, recumbency, pale mucus membranes and pinna, and tachycardia, enlarged lymph nodes, presence of ticks over body and pyrexia aroused suspicion of protozoal infection. Low haemoglobin $(7.2 \mathrm{~g} / \mathrm{dl})$, low haematocrit $(20.29 \%)$, increased leukocyte count (19.84 x103cu.mm.), increased red blood cell distribution width (33) and presence of "Koch's blue bodies" in lymph node biopsy material confirmed the case as theileriosis. Morphologically these piroplasms resembled parasite described by Soulsby et al., (1986) as theileria. Based on presence of Koch's blue bodies in the lymph node smear confirmed this case as caprine theileriosis. Clinical manifestations in the present case find support from earlier observations (Shruthi et al., 2017). Tachycardia and dyspnea were due to anemia.

Examination of blood smear and lymph node biopsy is the most common method of diagnosing theileriosis but it is associated with several biologic and technical limitations such as absence of circulating piroplasms at the time of initial presentation owing to low parasitaemia, false negative reports owing to extremely small and pleomorphic organism confused with artifacts (stain particles).The blood smear did not reveal any piroplasms as it might be due to the early phase of the infection in which the lymph nodes get affected with schizontal stage of theileriosis. Since the classical Koch's blue bodies were detected in the present case the case was diagnosed in the early stage itself and treated with buparvoquone successfully. The success of the present case is the early detection of lymph node aspiration biopsy smear for theileriosis and initiation of treatment resulted in early recovery of the ailing animal. A case of theileriosis and its management was recorded. 


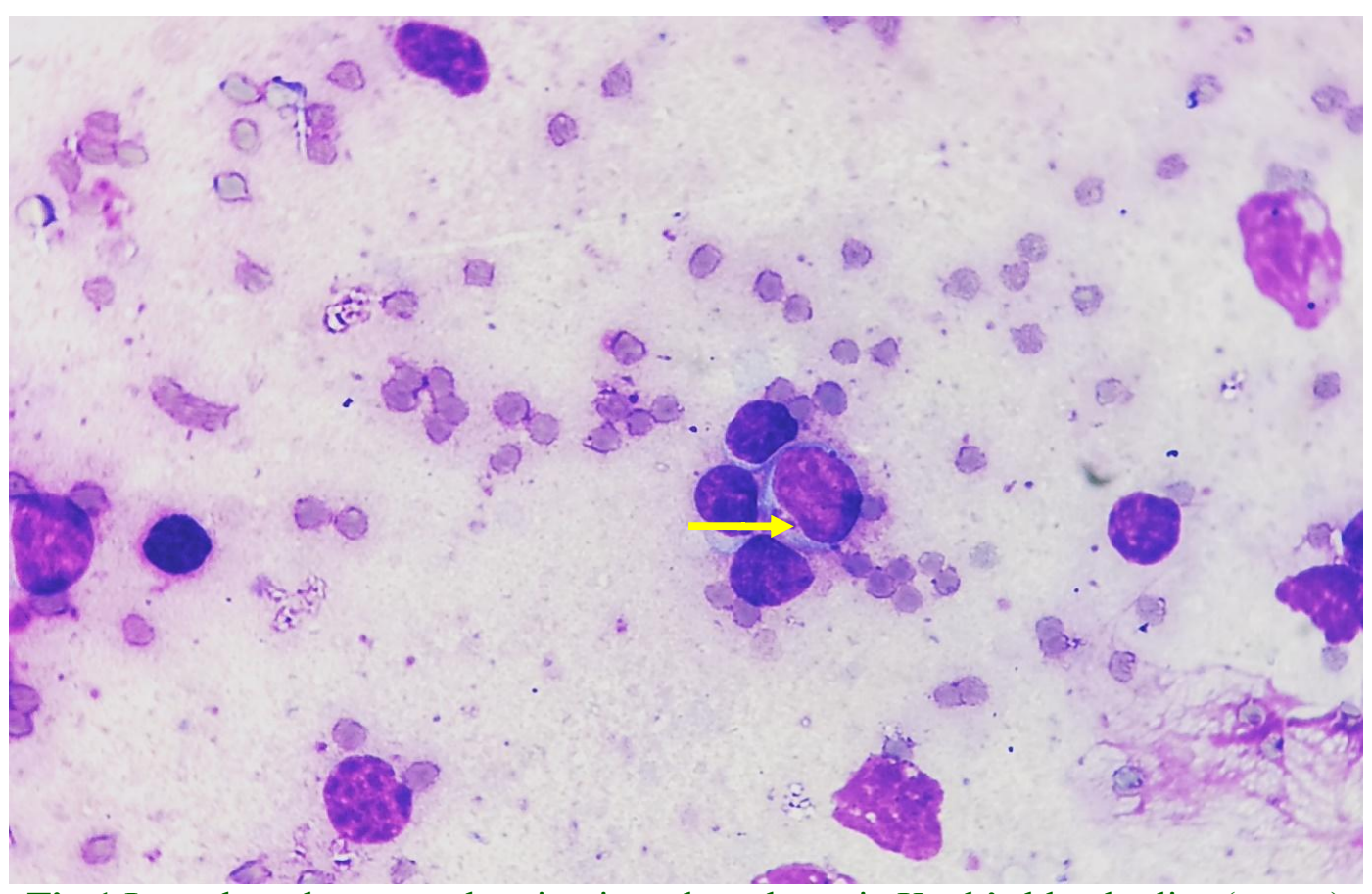

Fig.1 Lymph node smear showing intra lymphocytic Koch's blue bodies (arrow) $($ Leishman stain $\times 100 x)$

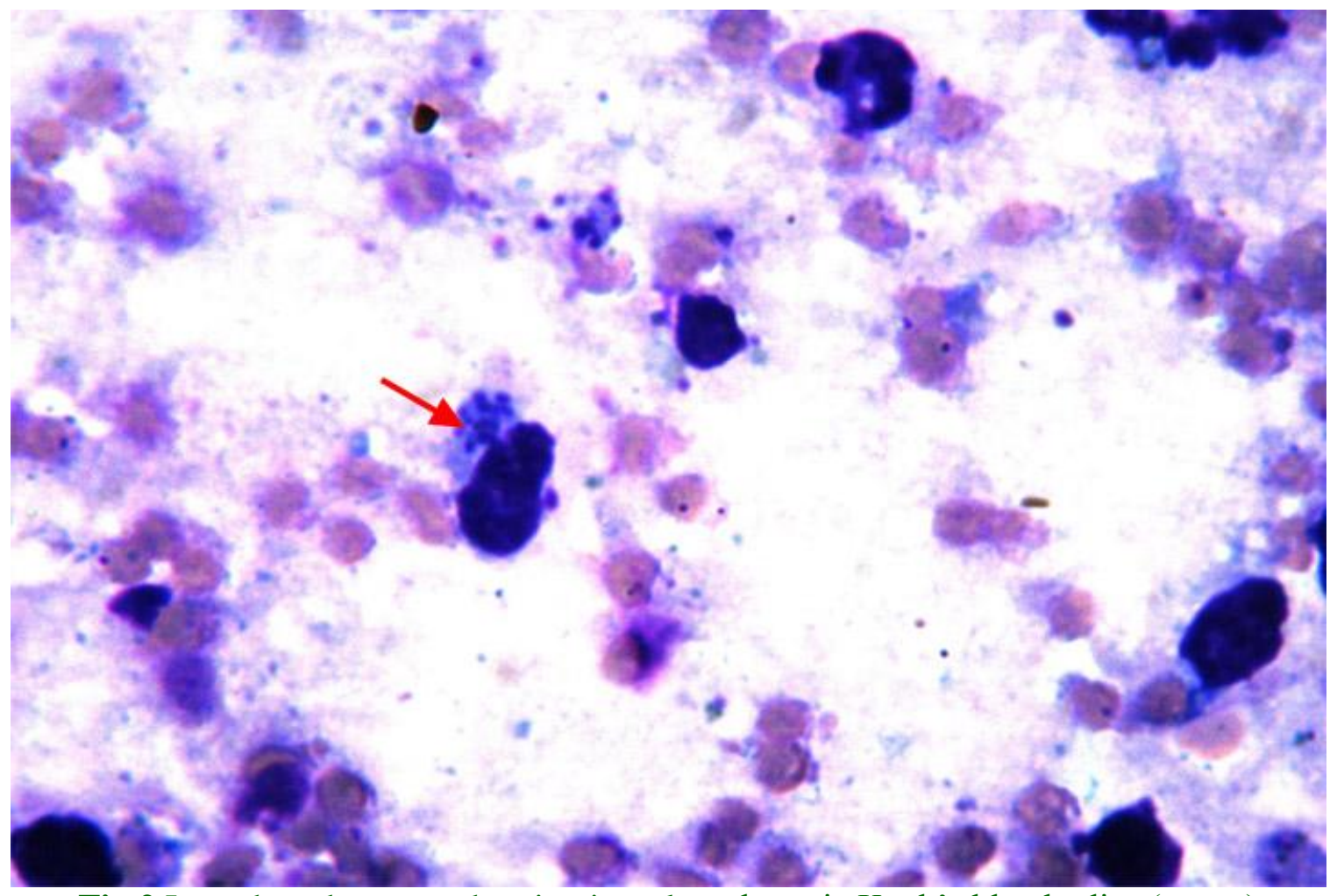

Fig.2 Lymph node smear showing intra lymphocytic Koch's blue bodies (arrow)

$($ Giemsa stain $\times 100 x)$ 


\section{Acknowledgements}

The author is thankful to, the Dean of Veterinary College and Research Institute, Namakkal for providing necessary facilities during the period of study.

\section{References}

Dolan, T. T. (1989). Theileriosis: a comprehensive review. Rev. Sci. Tech. Off. Int. Epizoot, 8, 11-36.

Kaufmann, J. (1996). Text book of parasitic infections of domestic animals. Birkhauser Verlag, Postfach, pp. 169-
170.

Shruthi, R., P. M. Thimmareddy, G. S. Mamatha, B. M. Chandranaik, and G. C. Puttalakshmamma, (2017). Studies on theileriosis in goats from Karnataka, South India. J. of Par.Dis., 41(4): 10821085.

Sisodia, R. S. (1981). Present status of sheep theileriosis in India- a review. Livestock adviser.

Soulsby, E. J. L. (1986). Helminths, Protozoa and Arthropods of Domesticated Animal.7th. Edition. Bailliere Tindall, London, pp. 736-737.

\section{How to cite this article:}

Banka, P.R., S. Sivaraman, G. Vijayakumar and Arulmozhi, A. 2020. Successful Therapeutic Management of Theileriosis in a Goat- A Case Report. Int.J.Curr.Microbiol.App.Sci. 9(05): 1481-1484. doi: https://doi.org/10.20546/ijcmas.2020.905.168 